\title{
Timely initiation of breastfeeding and associated factors among mothers of infants age 0-6 months old in Bahir Dar City, Northwest, Ethiopia, 2017: a community based cross-sectional study
}

Amare Belachew

\begin{abstract}
Background: Early initiation of breastfeeding, also known as early initiation, is the provision of a mothers own breast milk to her infant within one hour of birth. In Ethiopia, there is a considerable variation in the timely initiation of breastfeeding practices. Therefore, the objective of this study was to assess the level of timely initiation of breastfeeding and associated factors among mothers of infants less than six months old in Bahir Dar, Northwest, Ethiopia.

Methods: A community-based cross-sectional study was conducted in Bahir Dar City from April 15 to May 3, 2017. A total of 472 mothers of infant age less than six months were selected by simple random sampling technique. Data were collected using an interviewer administered questionnaire. Descriptive statistics were done to know the distribution of variables. To identify predictors logistic regression was conducted.

Results: The prevalence of timely initiation of breastfeeding was 356 (75.4\%). Mothers who birth by a vaginal delivery (Adjusted Odds Ratio [AOR] 6.99; 95\% Confidence Interval [CI] 3.49, 14.00), mothers who gave birth at health institution (AOR 3.36; 95\% Cl 1.47, 7.67), and who get breastfeeding counseling during antenatal care visits (AOR 5.64; 95\% Cl 2.70, 11.79) were more likely to initiate breastfeeding within one hour than counterparts.

Conclusions: Practice of timely initiation of breastfeeding in this study was suboptimal. Mothers who delivered at the health institution, gave birth by a vaginal delivery, and who got breastfeeding counseling during antenatal visits were the independent predictors of the timely initiation of breastfeeding practice. Encouraging all mothers to give birth in health facilities, counsel mothers to initiate breastfeeding timely at time of Caesarean sections, reduce the indication of the Caesarean procedure and providing breastfeeding counseling during antenatal care visits were recommended. Additionally, health services must establish practices that enable timely breastfeeding whenever possible, in particular, after Caesarean section and systems need to be set up to enable skin-to-skin and timely breastfeeding.
\end{abstract}

Keywords: Timely initiation breastfeeding, Infants less than six months, Bahir Dar, Ethiopia

(c) The Author(s). 2019 Open Access This article is distributed under the terms of the Creative Commons Attribution 4.0 International License (http://creativecommons.org/licenses/by/4.0/), which permits unrestricted use, distribution, and reproduction in any medium, provided you give appropriate credit to the original author(s) and the source, provide a link to the Creative Commons license, and indicate if changes were made. The Creative Commons Public Domain Dedication waiver (http://creativecommons.org/publicdomain/zero/1.0/) applies to the data made available in this article, unless otherwise stated. 


\section{Background}

Breastfeeding is important for the growth and development of newborn babies by providing vital nutrients. World Health Organization (WHO) recommend that breastfeeding should be initiated within the first hours of life and exclusive breastfeeding is enough, without any additional foods or drinks up to six months [1]. Breastfeeding helps to increase bonding between mother and infant, reduce infections like pneumonia and diarrhea, enhance growth and development of infants, and reduce the risk for obesity in later life [2].

Timely initiation of breastfeeding can help to prevent neonatal deaths caused by infections such as sepsis, pneumonia, and diarrhea. The study showed that when breastfeeding was initiated within the first hour, around $22 \%$ of neonatal mortality could be prevented [3].

Other studies were done on timely initiation and exclusive breastfeeding practices in many parts of the world, including in Ethiopia. Based on Ethiopian Demographic and Health Survey (EDHS) 2016 report, only $73 \%$ mothers started breastfeeding within one hour of birth [4]. Similarly, studies done in Motta town, Easten Gojjam zone 78.8\%, Debre Birhan town 62.6\% and Dembecha district $73.1 \%$ showed that infants started breastfeeding within one hour of birth respectively [5-7].

Studies done in Ethiopia showed that mothers when gave birth by traditional birth attendants, place of delivery was at home, didn't provide colostrum within the first hour, had inadequate information regarding breastfeeding practice and prelacteal feeding, could have an influence on timely initiation and exclusive breastfeeding practices [5, 8, 9]. In Ethiopia, there is a considerable variation of prevalence in timely initiation of breastfeeding practices and this has not achieved the plan set at Ethiopian Health Sector Development Plan (HSDP) IV, which is to increase in the proportion of timely initiation of breastfeeding to $92 \%$ by the end of 2015 [10]. Therefore, the aim of this study was to assess the prevalence of timely initiation of breastfeeding and associated factors among mothers of infant age 0-6 months old in Bahir Dar City, Ethiopia.

\section{Methods}

\section{Study area and design}

A community-based cross-sectional study was employed from April 15 to May 3, 2017. The study was conducted in Bahir Dar City, which is the capital city of Amhara, a national regional state, Ethiopia. It is $565 \mathrm{~km}$ away from Addis Ababa. The city has nine sub cities and with a total of 17 kebeles. The total population of Bahir Dar City was 308,877 . Of this population 151,350 (49\%) were males and 157,527 (51\%) were females. The city has government and private health institutions. It has two government and private hospitals, and nine health centers.

\section{Sampling size and sampling procedure}

The sample size was calculated using single proportion formula with the assumption of $95 \%$ confidence level, $5 \%$ margin of error, $82 \%$ proportion of timely initiated breastfeeding practice in Ambo [11] and using design effect of two, then $10 \%$ non-response rate was added and finally it became 499. Since it is multistage (among nine sub-cities, six sub-cities were selected and then kebeles in selected sub cities was selected by lottery methods). The total sample size was proportionally allocated in each selected kebeles. Simple random sampling i.e., lottery method was used to select study participants. Eligible mothers of having an infant less than six months old were traced from health extension workers. The actual age of the infants was determined by asking the mothers and reviewing the birth date certificate.

\section{Data measures}

An interviewer administered questionnaire was used to collect the data. The questionnaire was developed from reviewing from previous research done on a similar topic [4-7]. Data collectors and supervisors were trained on how to extract information from respondents, ethical aspects and ways of communication one-day training prior to study commencement.

\section{Statistical analysis}

The questionnaire was checked visually for completeness and coding was given at the right margin of the questionnaire. Data was entered into Epi info version 3.5.3 and exported to SPSS version 21.0 statistical software packages for analysis. Crude (COR) and adjusted odds ratio (ARO) with $95 \%$ confidence interval (CI) was calculated to determine the strength of association between a response variable and predictor variables. Variable with a $p$ value less than 0.05 was declared as a level of significance.

\section{Variables \\ Dependent variables}

Timely initiation of breastfeeding practice.

\section{Independent variables}

Sociodemographic characteristics of mother's i.e. income, education, religion, marital status, family type, age, ethnicity, occupation, information etc.

Healthcare service use by the mother's e.g. number of antenatal visits, mode of delivery, place of delivery, breastfeeding counseling during antenatal visits, prelacteal feeding, colostrum feeding etc.

Sociodemographic characteristics of infants i.e. gender of newborn etc.

Timely (early) initiation of a breastfeeding: a mother who put her baby to breast within one hour following delivery [5]. 
Table 1 Sociodemographic characteristics of mothers (respondents) who have infants less than six months old, in Bahir Dar town, Northwest, Ethiopia, 2017

\begin{tabular}{|c|c|c|c|}
\hline Variable & Category $(n=472)$ & Frequency & Percent \\
\hline \multirow[t]{2}{*}{ Infant sex } & Male & 214 & 45.3 \\
\hline & Female & 258 & 54.7 \\
\hline \multirow[t]{3}{*}{ Infant age } & 0-30 days & 71 & 15 \\
\hline & $31-90$ days & 140 & 29.7 \\
\hline & $91-180$ days & 261 & 55.3 \\
\hline \multirow[t]{5}{*}{ Age of mothers } & $15-19$ & 30 & 6.4 \\
\hline & $20-24$ & 119 & 25.2 \\
\hline & $25-29$ & 163 & 34.5 \\
\hline & $30-34$ & 98 & 20.8 \\
\hline & 35 and above & 62 & 13.1 \\
\hline \multirow[t]{4}{*}{ Religion } & Orthodox & 355 & 75.2 \\
\hline & Muslim & 94 & 20 \\
\hline & Protestant & 12 & 2.5 \\
\hline & Catholic & 11 & 2.3 \\
\hline \multirow[t]{4}{*}{ Ethnicity } & Amhara & 455 & 96.4 \\
\hline & Tigre & 6 & 1.3 \\
\hline & Oromo & 6 & 1.3 \\
\hline & Others & 5 & 1 \\
\hline \multirow{5}{*}{$\begin{array}{l}\text { Level of education } \\
\text { of mothers }\end{array}$} & No education & 86 & 18.2 \\
\hline & Able to read \& write & 55 & 11.7 \\
\hline & Primary school (1-8) & 108 & 22.9 \\
\hline & Secondary & 86 & 18.2 \\
\hline & Higher & 137 & 29 \\
\hline \multirow{5}{*}{$\begin{array}{l}\text { Occupational status } \\
\text { of mothers }\end{array}$} & Housewife & 252 & 53.4 \\
\hline & Governmental employee & 108 & 22.9 \\
\hline & Private employee & 46 & 9.7 \\
\hline & Merchant & 38 & 8.1 \\
\hline & Daily labor & 28 & 5.9 \\
\hline \multirow{4}{*}{$\begin{array}{l}\text { Marital status of } \\
\text { mother }\end{array}$} & single & 36 & 7.6 \\
\hline & Married & 409 & 86.7 \\
\hline & Widowed & 6 & 1.3 \\
\hline & Divorced & 21 & 4.4 \\
\hline \multirow{5}{*}{$\begin{array}{l}\text { Husband educational } \\
\text { level (409) }\end{array}$} & No education & 30 & 7.3 \\
\hline & Able to read \& write & 51 & 12.5 \\
\hline & Primary school (1-8) & 103 & 25.1 \\
\hline & Secondary & 85 & 20.80 \\
\hline & Higher & 140 & 34.3 \\
\hline \multirow{5}{*}{$\begin{array}{l}\text { Husband occupation } \\
\text { (409) }\end{array}$} & Gov.t employee & 118 & 28.9 \\
\hline & Private employee & 77 & 18.8 \\
\hline & Merchant & 116 & 28.4 \\
\hline & Daily labor & 64 & 15.6 \\
\hline & Farmer \& driver & 34 & 8.3 \\
\hline
\end{tabular}

Table 1 Sociodemographic characteristics of mothers (respondents) who have infants less than six months old, in Bahir Dar town, Northwest, Ethiopia, 2017 (Continued)

\begin{tabular}{llll}
\hline Variable & Category $(n=472)$ & Frequency & Percent \\
\hline Type of family & Nuclear family & 298 & 63.1 \\
& Extended family & 174 & 36.9 \\
Household income & $\leq 1000$ & 59 & 12.5 \\
& $1001-2000$ & 160 & 33.9 \\
& $2001-3000$ & 62 & 13.1 \\
& $>3000$ & 191 & 40.5 \\
\hline
\end{tabular}

Prelacteal feeding: an infant within the first three days of life being fed something other than breast milk [5].

Colostrum feeding: mother provides the first breast milk which is thick, sticky and clear yellowish in color contains (maternal antibody, vitamin A, protein) to their infant within one hour [1].

\section{Results}

Sociodemographic characteristics

Among 499 eligible mothers, 472 were agreed to participate in this study, which made a response rate of $94.5 \%$. Regarding infant gender, around $45.3 \%$ of children were males and $54.7 \%$ of children were females. The majority 261 (55.3\%) of children were aged between four to six months. The mean age of mothers was 27.5 years, 163 $(34.5 \%)$ were within the age group of 25-29 years. One hundred and eight (22.9\%) mothers had attended primary education and $53.4 \%$ were housewife mothers. From 472 mothers, 298 (63.1\%) were living in a nuclear family. The average house income of the respondents was 1750 Ethiopian birr per month and 59 (12.5\%) respondents earn less than or equal to 1000 birr per month (Table 1).

\section{Breastfeeding related practices}

All mothers have breastfed their current infant for a period of time. From a total of 472 mothers, 356 (75.4\%) initiated breastfeeding within one hour of birth. Most mothers 396 (83.9\%) fed colostrum/first milk to their newborn. The majority, $74.6 \%$ did not give a prelacteal food other than breast milk within three days of an infant life. The prevalence of exclusive breastfeeding practice one day before the survey was $86.4 \%$ (Table 2).

\section{Factors associated with timely initiation of breastfeed practice}

First variables tested by using bivariate analysis and in bivariate analysis variables with $(p<0.05)$ is considered into multivariate logistic regression analysis:

In bivariate analysis the factors found to be associated with initiation of breastfeeding within one hour were; 
Table 2 Breastfeeding and related practice among mothers who have an infant less than six months in Bahir Dar City, Northwest, Ethiopia, 2017

\begin{tabular}{|c|c|c|c|}
\hline Variable & Category & Frequency & Percent \\
\hline \multirow[t]{2}{*}{ Antenatal visits } & Yes & 370 & 78.4 \\
\hline & No & 102 & 21.6 \\
\hline \multirow{2}{*}{$\begin{array}{l}\text { Number of antenatal } \\
\text { visits (370) }\end{array}$} & $\leq 3$ & 219 & 59 \\
\hline & $\geq 4$ & 151 & 41 \\
\hline \multirow{2}{*}{$\begin{array}{l}\text { Breastfeeding counseling } \\
\text { during antenatal visits } \\
\text { (370) }\end{array}$} & Yes & 203 & 54.9 \\
\hline & No & 167 & 45.1 \\
\hline \multirow[t]{2}{*}{ Place of delivery } & Home & 119 & 25.2 \\
\hline & Health institution & 353 & 74.8 \\
\hline \multirow[t]{2}{*}{ Mode of delivery } & Vaginal & 287 & 60.8 \\
\hline & Caesarean section & 185 & 39.2 \\
\hline \multirow{2}{*}{$\begin{array}{l}\text { Breastfeeding } \\
\text { experience of } \\
\text { current infant }\end{array}$} & Yes & 461 & 97.7 \\
\hline & No & 11 & 2.3 \\
\hline \multirow{2}{*}{$\begin{array}{l}\text { Timely initiation of } \\
\text { breastfeeding within } \\
1 \mathrm{~h}\end{array}$} & yes & 356 & 75.4 \\
\hline & No & 116 & 24.6 \\
\hline \multirow[t]{2}{*}{ Colostrum feeding } & Yes & 396 & 83.9 \\
\hline & No & 76 & 16.1 \\
\hline \multirow[t]{2}{*}{ Prelacteal feeding } & Yes & 120 & 25.4 \\
\hline & No & 352 & 74.6 \\
\hline \multirow{2}{*}{$\begin{array}{l}\text { Infant feeding in } \\
\text { the previous } 24 \mathrm{~h} \text {. }\end{array}$} & Exclusively BF & 408 & 86.4 \\
\hline & $\begin{array}{l}\text { In addition to breast } \\
\text { milk water, sugar } \\
\text { solution, tea, soft foods. }\end{array}$ & 64 & 13.6 \\
\hline \multirow{6}{*}{$\begin{array}{l}\text { Reasons for not } \\
\text { exclusively BF (64) }\end{array}$} & Not sufficient for infant & 19 & 29.7 \\
\hline & culture/tradition & 17 & 26.7 \\
\hline & Lack of time & 12 & 18.7 \\
\hline & Maternal illness & 9 & 14.1 \\
\hline & Infant becomes thirsty & 5 & 7.8 \\
\hline & Nipple breast problem & 2 & 3 \\
\hline
\end{tabular}

place of delivery, mode of delivery, occupational status, mother's educational status, maternal age and breastfeeding counseling during antenatal visits.

Finally, mode of delivery, place of delivery, and counseling of breastfeeding during antenatal visits were identified as predictor variables in multivariate analysis.

Mode of delivery were significantly associated with timely initiating of breastfeeding. The odds of timely initiation were 6.9 times higher for women giving birth vaginally than those who had a caesarian section (AOR 6.9, 95\% CI 3.49, 14.00).

Place of delivery was significantly associated with timely initiation of breastfeeding practices. Mothers who give birth at a health institution were 3.4 times more likely to initiate breastfeeding within one hour than mothers who delivered at home (AOR 3.36, 95\% CI 1.47, 7.67).
Counseling of mothers during antenatal care visits was significantly associated with timely initiation of breastfeeding. Mothers who were counseled during antenatal visits were 5.6 times more likely to initiate breast milk within one hour than mothers who had not counseled during antenatal visits (AOR 5.64, 95\% CI 2.70, 11.79) (Table 3).

\section{Discussion}

Timely initiation of breastfeeding is vital for the survival of infants. In spite of this importance, the practice of timely initiation of breastfeeding in the study area was not satisfactory. Only $75.4 \%$ of mothers initiated timely breast milk, which is lower than the Ethiopian HSDP IV target level; to increase breastfeeding within the first hour of life from 52.1 to $92 \%$ by 2015 [10]. This rate in the southern part of Ethiopia is $83.7 \%$ [12, 13]. This finding is comparable with studies done in Motta (78.8\%) [5], Bangladesh 71\% [14], EDHS 73\% [4] and Dembecha district, 73.1\% [7]. However, this finding is higher than studies done in Arba Minch 57.6\% [15], Tanzania 51\% [16], and Bangladesh 67.3\% [17]. The difference may be due to maternal sociodemographic characteristics like i.e. access to information, socio-economic status, infrastructure, educational status, cross cultural difference in breastfeeding practice, and health service utilization characteristics.

Place of delivery was significantly associated with timely initiation of breastfeeding in the study area. A mother who gave birth at a health institution was 3.4 times more likely to initiate timely breastfeeding than when delivered at home. This finding is similar to a study done in Motta [5], Debre Birhan [6], Bangladesh [17], Axum [9], Uganda [18] and Nepal [19]. Mothers who delivered at a health institution may be supported and made aware of importance of early initiation of breastfeeding, and also health professionals tend to facilitate early initiation of breastfeeding compared to those who gave birth at home. Another possible explanation is mothers who delivered at home more commonly practiced prelacteal feeding and this may lead to a delay in initiation of breastfeeding which is supported by research done in Ethiopia, which revealed that mothers who gave birth at home were more likely to practice prelacteal feeding than their counterparts $[8,20]$. Therefore, counseling of mothers about the place of delivery during the antenatal visit, to give birth at a health institution, is crucial to optimize early initiation of breastfeeding.

Modes of delivery were also significantly associated with timely initiation of breastfeeding. A mother who gave birth via vaginal delivery was around seven times more likely to initiate breastfeeding within one hour than those gave birth via cesarean section. This finding is in line with studies done in Motta [5] and a systematic 
Table 3 Factors that affect timely initiation of breastfeeding practice among mothers of infants aged less than 6 months using bivariate and multivariate logistic regression analysis, Bahir Dar, Ethiopia, 2017

\begin{tabular}{|c|c|c|c|c|c|}
\hline \multirow[t]{2}{*}{ Variables } & \multicolumn{5}{|c|}{ Timely initiation of breastfeeding } \\
\hline & & Yes $n(\%)$ & No $n(\%)$ & Crude Odds Ratio (95\% Cl) & Adjusted Odds Ratio (95\% Cl) \\
\hline \multirow[t]{2}{*}{ Place of delivery } & Home & $79(66.4)$ & $40(33.6)$ & 1 & 1 \\
\hline & Health institution & $276(78.2)$ & $77(21.8)$ & $1.81(1.019,2.681)$ & $3.36(1.476,7.672)^{*}$ \\
\hline \multirow[t]{2}{*}{ Mode of delivery } & Vaginal delivery & $225(78.4)$ & $62(21.6)$ & $1.46(1.041,2.522)$ & $6.99(3.496,14.007)^{*}$ \\
\hline & Caesarean section & $132(71.4)$ & $53(28.6)$ & 1 & 1 \\
\hline \multirow[t]{2}{*}{ Occupational status } & Unemployed & 209 (82.9) & $43(17.1)$ & $2.41(1.272,3.095)$ & $2.26(0.998,4.310)$ \\
\hline & Employed & $147(71)$ & $73(29)$ & 1 & 1 \\
\hline \multirow[t]{2}{*}{ Mother's educational status } & Uneducated & $99(70.2)$ & $42(29.8)$ & 1 & 1 \\
\hline & Educated & $257(77.6)$ & $74(22.4)$ & $1.47(1.041,2.609)$ & $1.91(0993,3.708)$ \\
\hline \multirow[t]{2}{*}{ Maternal age } & $15-29 y r s$ & $220(70.5)$ & $92(29.5)$ & 1 & 1 \\
\hline & $\geq 30 y r s$ & $130(81.2)$ & $30(18.8)$ & $1.81(1.168,3.014)$ & $1.49(0.764,2.926)$ \\
\hline \multirow{2}{*}{$\begin{array}{l}\text { Breastfeeding counseling } \\
\text { during antenatal visit }\end{array}$} & Yes & $176(86.7)$ & $27(13.3)$ & $1.85(1.069,3.187)$ & $5.64(2.702,11.798)^{*}$ \\
\hline & No & $130(77.8)$ & $37(22.2)$ & 1 & 1 \\
\hline
\end{tabular}

$1=$ reference ${ }^{*}=p$ - value less than $0.05 n=$ number $\%=$ percent

review done of Medline LILACS Scopus and Web of Science electronic databases [21]. This may be due to the procedure taking longer, pain after procedure, effects of anesthesia and tiredness that make it difficult to initiate breastfeeding early. It may be also health professionals may be busy with lifesaving activities and lack attention to initiate breastfeeding early. Therefore, health professionals and pregnant mothers could be informed about the negative association between a caesarian delivery and breastfeeding and its impact on infant wellbeing, as well as changing hospital policies and practices which are also necessary.

In this study, mothers who were counseled during antenatal visits were 5.6 times more likely to initiate timely breastfeeding than those who were not counseled during antenatal visits. This finding is consistent with studies done in Ethiopia; Motta [5], Raya Kobo [8], and Axum [9]. This may be due to mothers who had antenatal visits receive enough information about the importance of early initiation of breastfeeding and have also adequate knowledge about breastfeeding, which may lead to early initiation of breastfeeding compared to counterparts.

\section{Conclusion}

Prevalence of timely initiation of breastfeeding in the study area was lower than the national recommended level. Place of delivery, mode of delivery and breastfeeding counseling during antenatal visits were the determinant factors for timely initiation of breastfeeding practices. Community based breastfeeding education about timely initiation of breastfeeding to pregnant women, encouraging all mothers to give birth in health facilities, counseling mothers to initiate breastfeeding timely at the time of caesarian sections and providing breastfeeding counseling during antenatal visits are recommended to increase timely initiation of breastfeeding. Additionally, health services must establish practices that enable timely breastfeeding whenever possible, particularly after Caesarean a section and systems need to be set up to enable skin-to-skin and timely breastfeeding.

\section{Abbreviations}

ANC: Antenatal care service; C/S: Caesarean section; EBF: Exclusive Breast Feeding; EDHS: Ethiopian Demographic and Health Survey; HSDP: Health sector development plan; WHO: World Health Organization

\section{Acknowledgments}

This study received financial support from Bahir Dar University, College of Medicine and Health Sciences, School of Nursing. My thanks also go to librarian staff and study participants for their cooperation during the study. Finally, my gratitude also goes to data collectors and students.

\section{Funding}

Not applicable.

\section{Availability of data and materials}

The data of this study cannot be shared publically due to the presence of confidential issues of the study participant's information.

\section{Author's contribution}

$\mathrm{AB}$ contributed to the design, collected, analyzed, interpreted data, drafted the manuscript for important intellectual content, and approved the final version for submission.

\section{Ethics approval and consent to participate}

Ethical approval of the study was obtained from Bahir Dar University, college of medicine and health science department of nursing ethical review committee. The ethical letter was submitted to Bahir Dar health bureau and permission was obtained to conduct the study. To ensure confidentiality of patient's information was kept and was not exposed to third body.

\section{Consent for publication}

It is not applicable.

Competing interests

The author declares that he/she has no competing interests. 


\section{Publisher's Note}

Springer Nature remains neutral with regard to jurisdictional claims in published maps and institutional affiliations.

Received: 29 June 2018 Accepted: 9 December 2018

Published online: 14 January 2019

\section{References}

1. Organisation mondiale de la santé. Département santé et développement, World Health Organisation Staff, World Health Organization, UNICEF. Global strategy for infant and young child feeding. World Health Organization; 2003.

2. Victora CG, Bahl R, Barros AJ, França GV, Horton S, Krasevec J, et al. Breastfeeding in the 21st century: epidemiology, mechanisms, and lifelong effect. Lancet. 2016;387(10017):475-90

3. Edmond KM, Zandoh C, Quigley MA, Amenga-Etego S, Owusu-Agyei S, Kirkwood BR. Delayed breastfeeding initiation increases risk of neonatal mortality. Pediatrics. 2006;117(3):e380-6.

4. Ethiopian Demography and Health Survey: Addis Ababa. Ethiopia and Rockville, Maryland, USA: Central statistics agency and ICF. EDHS; 2016.

5. Tewabe T. Timely initiation of breastfeeding and associated factors among mothers in Motta town, East Gojjam zone, Amhara regional state, Ethiopia 2015: a cross-sectional study. BMC Pregnancy and Childbirth. 2016;16:314.

6. Tilahun G, Degu G, Azale T, Tigabu A. Prevalence and associated factors of timely initiation of breastfeeding among mothers at Debre Berhan town, Ethiopia: a cross-sectional study. Int Breastfeed J. 2016;11:27.

7. Bimerew A, Teshome M, Kassa GM. Prevalence of timely breastfeeding initiation and associated factors in Dembecha district, North West Ethiopia: a cross-sectional study. Int Breastfeed J. 2016;11:28.

8. Legesse M, Demena M, Mesfin F, Haile D. Factors associated with colostrum avoidance among mothers of children aged less than 24 months in Raya kobo district, North-Eastern Ethiopia: community-based cross-sectional study. J Trop Pediatr. 2015;61:357-63.

9. Alemayehu M, Abreha K, Yebyo H, Zemichael K, Gebremichael H. Factors associated with timely initiation and exclusive breastfeeding among mothers of Axum town, Northern Ethiopia. Sci J Public Health. 2014:2:394-401.

10. Federal Democratic Republic of Ethiopia Ministry of Health. Health Sector Development Program IV, 2010/11-2014/15, https://www. healthynewbornnetwork.org/resource/federal-democratic-republic-ethiopiaministry-health-health-

11. Regassa N. Infant and child feeding practices among farming communities in southern Ethiopia. Kontakt. 2014;16(4):e215-22.

12. Beyene MG, Geda NR, Habtewold TD, Assen ZM. Early initiation of breastfeeding among mothers of children under the age of 24 months in Southern Ethiopia. Int Breastfeed J. 2016;12(1).

13. Batal M, Boulghourjian C, Abdallah A, Afifi R. Breast-feeding and feeding practices of infants in a developing country: a national survey in Lebanon. Public Health Nutr. 2006;9:313-9.

14. Kabir I, Khanam M, Agho KE, Mihrshahi S, Dibley MJ, Roy SK. Determinants of inappropriate complementary feeding practices in infant and young children in Bangladesh: secondary data analysis of demographic health Survey 2007. Matern Child Nutr. 2012;8:11-27.

15. Adugna DT. Women's perception and risk factors for delayed initiation of breastfeeding in Arba Minch Zuria, southern Ethiopia. Int Breastfeed J. 2014:9:8.

16. Exavery A, Kanté AM, Hingora A, Phillips JF. Determinants of early initiation of breastfeeding in rural Tanzania. Int Breastfeed J. 2015;10:27.

17. Karim F, Billah SM, Chowdhury MA, Zaka N, Manu A, El Arifeen S, et al. Initiation of breastfeeding within one hour of birth and its determinants among normal vaginal deliveries at primary and secondary health facilities in Bangladesh: a case-observation study. PLOS One. 2018:13:e0202508.

18. Kalisa R, Malande O, Nankunda J, Tumwine JK. Magnitude and factors associated with delayed initiation of breastfeeding among mothers who deliver in Mulago hospital, Uganda. Afr Health Sci. 2015;15:1130-5.

19. Khanal V, Scott JA, Lee AH, Karkee R, Binns CW. Factors associated with early initiation of breastfeeding in Western Nepal. Int J Environ Res Public Health. 2015;12:9562-74

20. Tariku A, Biks GA, Wassie MM, Gebeyehu A, Getie AA. Factors associated with prelacteal feeding in the rural population of Northwest Ethiopia: a community cross-sectional study. Int Breastfeed J. 2016;11:14.

21. Esteves TM, Daumas RP, Oliveira MI, Andrade CA, Leite IC. Factors associated to breastfeeding in the first hour of life: systematic review. Rev Saude Publica. 2014;48:697-708.

Ready to submit your research? Choose BMC and benefit from:

- fast, convenient online submission

- thorough peer review by experienced researchers in your field

- rapid publication on acceptance

- support for research data, including large and complex data types

- gold Open Access which fosters wider collaboration and increased citations

- maximum visibility for your research: over $100 \mathrm{M}$ website views per year

At BMC, research is always in progress.

Learn more biomedcentral.com/submissions 